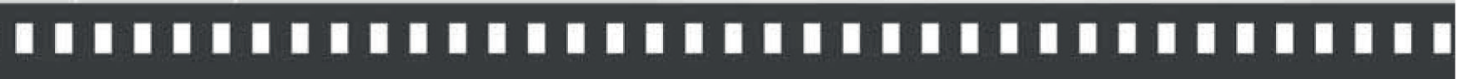
Potografia, didatismo e polissemia
na série esportiva Microcosmo,
do jornal Folha de S.Paulo

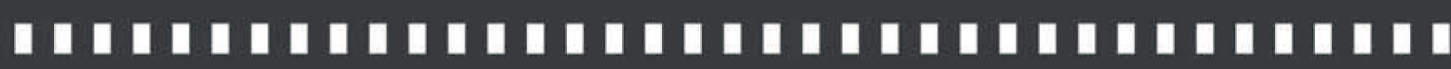

\author{
Janayna da Silva Ávila
}

Artigo recebido em: 01/06/2016

Artigo aprovado em: 08/10/2016 


\title{
Fotografia, didatismo e polissemia na série esportiva Microcosmo, do jornal Folha de S.Paulo
}

\author{
Photography, didacticism and polysemy \\ in the sports series Microcosmo, \\ from the Folha de S.Paulo newspaper
}

Janayna da Silva Ávila*

Resumo: Este artigo analisa as fotografias que compõem a série especial Microcosmo, da editoria de esportes da versão digital do jornal Folha de S.Paulo e que é alusiva aos Jogos Olímpicos do Rio 2016. Por meio da análise formal das imagens, investigamos o didatismo presente na edição, a polissemia resultante desse processo e o quanto a fotografia contribui para a construção de discursos.

Palavras-chave: Fotografia; Esporte; Jornalismo; Olimpiada.

Abstract: This article analyses the pictures that compose the series Microcosmo, from the sports section of the digital version of the Folha de S.Paulo newspaper and that refers to the Rio 2016 Olympic Games. Through a formal analysis of the images, we investigated the didacticism present in this particular edition, its resultant polysemy and the way photography contributes when creating discourses.

Key-words: Photography; Sports; Journalism; Olympics.

* Graduada em jornalismo, com mestrado e doutorado em Estudos Literários. Professora efetiva do curso de Jornalismo da Universidade Federal de Alagoas, leciona as disciplinas Comunicação e Cultura Visual, Fotografia e Fotojornalismo. Lidera o grupo de pesquisa Mídia, fotografia e estudos culturais. 


\section{Introdução}

Em muitas das odes olímpicas do poeta grego Píndaro (522 a.C. - 443 a.C.), a opulência, a beleza, a perfeição e a habilidade descomunal dos deuses se manifestam nos atletas que conquistam suas vitórias em jogos competitivos. E assim, os atletas, entes mortais, transformam-se em heróis e, transformando-se em heróis, adquirem status de semideuses, a "antessala" da divindade, por meio da força atlética que só poderia se originar de uma relação próxima com o mundo espiritual, divino. Na Grécia, não à toa, os jogos eram tão indissociáveis de aspectos religiosos que boa parte da competição acontecia próxima a templos sagrados, sendo dedicada em honra de Zeus, o "pai" de todos os deuses.

Entre deuses e mortais, o exercício da força unia-os, justificada pela busca permanente da vitória, de exceder, ultrapassar os limites humanos, como apresenta Gumbrecht:

A expectativa de que os deuses iriam querer se envolver na competição atlética era consistente com aquilo que os gregos acreditam saber sobre a maioria deles: basta pensar em Hermes, Afrodite, Hefesto, Posêidon e, principalmente, em Zeus, para se dar conta de como as identidades desses deuses eram construídas em cima de vários tipos de potência física. Tanto a Ilíada quanto Odisseia deixam claro que esses deuses estavam constantemente competindo entre si por meio de sua força física, e que o agon (isto é, a luta e a competição) era sua forma preferida de vida e muitas vezes, de fato, a única razão do seu interesse pelos humanos (GUMBRECHT, 2015, p.16-17).

Hoje não se pode, evidentemente, aludir a expressões como "força divina" ou "vitória milagrosa" para se referir a atletas em competições esportivas. Cada vez mais técnico e embasado por um sistema de treinos planejado cientificamente, o esporte 
desvencilhou-se, no decorrer de sua história, de aspectos abstratos, de caráter espiritual.

Ao mesmo tempo, o esporte representa atualmente um muito bem sucedido produto de entretenimento e, consequentemente, de geração de lucros. Uma prova disso está na disputa acirrada, com campanhas envolvendo governos, mídia e poderosos grupos econômicos, para sediar grandes eventos esportivos, como os Jogos Olímpicos e a Copa do Mundo de Futebol.

Em algumas situações, as campanhas estão envoltas em denúncias de corrupção, como propinas e escolhas fraudulentas, a exemplo das notícias recentes envolvendo o poder público em Tóquio, no Japão, e o Comitê Olímpico Internacional (COI). Em 2013, a capital japonesa superou dois candidatos de peso, Istambul e Madrid, e acabou sendo a escolhida para ser sede dos Jogos Olímpicos de 2020. Em reportagem publicada no jornal inglês The Guardian, em 11 de maio de 2016, há indícios de pagamentos na ordem de 1,3 milhão de euros destinados à compra de votos no processo de escolha da sede.

Evidentemente, nãoé a primeira vez que notícias semelhantes surgem na cobertura esportiva - a Copa do Mundo de Futebol, especialmente nos últimos anos, também foi relacionada a disputas suspeitas, o que só reafirma seu caráter de produto de entretenimento potencialmente lucrativo, e que se agigantou também como produto midiático, objeto de nosso interesse. A partir da demanda por horas de lazer e da identificação do público em geral por competições esportivas, sua espetacularização midiática avança sobre o público com ferramentas sedutoras e quase sempre eficientes, alcançando a audiência pretendida, numa engrenagem que funciona sempre com o combustível da emoção, da identificação que, desde a Idade Antiga, os homens tinham para com o esporte.

É inegável também a forte relação entre esporte e fotografia. Desde os primórdios da fotografia, quando os equipamentos saíram dos estúdios e passaram a permitir, com qualidade, o registro de objetos em movimento, a prática esportiva tornou-se um dos 
principais assuntos de interesse de fotógrafos profissionais e amadores. As primeiras fotografias esportivas que circularam o mundo à época foram feitas pelo fotógrafo francês Jacques Henri Lartigue (1894-1986), com sua icônica série sobre os Jogos Olímpicos da Antuérpia, Bélgica, realizados em 1920.

Narrador visual da vida em movimento, o esporte era um tema inspirador para Lartigue, que documentou, com cuidadoso apuro estético, partidas de tênis, saltos ornamentais, atletismo, remo e outras modalidades. De lá para cá, esporte e fotojornalismo, impulsionados pelos avanços tecnológicos e pela demanda do público, tornaram-se indissociáveis.

Graças a lentes teleobjetivas cada vez mais potentes, a cobertura fotojornalística esportiva é capaz de captar imagens que telespectadores ou até mesmo o público presente ao evento - ou não - são capazes de enxergar. Comumente, as imagens podem espetacularizar o esporte, emprestando forte carga dramática às imagens.

Hoje, com o aperfeiçoamento das técnicas e dos recursos tecnológicos, tanto jornais e revistas impressos quanto suas versões digitais se utilizam de projetos gráficos que buscam a perfeita legibilidade por meio de uma comunicação visual harmônica e eficiente na transmissão da informação, como argumenta Quadros (2004, p.4):

[...] a informação visual ajuda os leitores na sua vida diária. Ela organiza o conteúdo com rapidez e torna seu consumo mais fácil, inclusive daquelas porções menos interessantes. A preocupação com o tempo dos leitores se converteu num fator essencial no desenvolvimento de um projeto gráfico de um jornal. É preciso saber desenhar as informações, organizálas na página, articulá-las no contexto do veículo e promover o acesso rápido às áreas de interesse do leitor. 
Assim, elementos da trama gráfica como texto, fotografias, infográficos e ilustrações devem interagir entre si para serem assimilados pelo leitor. Todas as vezes que tais elementos são dispostos de forma desequilibrada, comumente se tem uma série de problemas nesse processo, desde a incompreensão dos conteúdos até a assimilação truncada dos mesmos, causada, muitas vezes, por ruídos.

\section{Revelações: didatismo e representação}

Desde dezembro de 2015 o jornal Folha de S.Paulo vem publicando projetos especiais sobre os Jogos Olímpicos, tanto na versão impressa quanto na digital. Em fevereiro de 2016, uma série publicada na editoria de esporte do site da Folha, na seção Microcosmo, e intitulada Segredos do esporte, chamou a atenção pelo fato de buscar revelar técnicas (ou "truques", como o texto denomina algumas vezes) próprias da natureza de determinadas modalidades esportivas e antes só conhecidas nos bastidores, por atletas, técnicos, árbitros, organizadores e jornalistas habituados a cobrir a área.

Em entrevista realizada por e-mail ${ }^{1}$, a jornalista Mariana Lajolo, editora do especial Microcosmo, explicou que o objetivo da publicação era "mostrar detalhes que muitas vezes passam despercebidos pelos olhos do torcedor, mas são essenciais para os atletas. Queríamos mostrar aspectos desconhecidos de boa parte dos leitores para ampliar o conhecimento deles sobre os esportes".

O título da série - Microcosmo - oferece uma boa pista sobre o quê o leitor poderá encontrar. Milésima parte do milímetro e unidade usada na microscopia, micro é também sinônimo de pequenez, fazendo alusão a algo que não pode ser visto a olho nu. O microcosmo pode ser entendido como "mundo em miniatura".

Com textos curtos, que funcionam quase como texto-legenda,

1 A entrevista foi realizada via e-mail, em maio, exclusivamente para a produção deste artigo. 
acrescentando informações às imagens, a série é essencialmente visual e audiovisual: fotografias, alguns infográficos e vídeos produzidos exclusivamente para o especial são seus principais conteúdos. Várias modalidades esportivas têm seus "segredos" revelados: ginástica artística, ginástica rítmica, handebol, hipismo, judô, nado sincronizado, pólo aquático, salto ornamental, tênis de mesa e tiro olímpico.

Como a proposta da série é inserir o leitor nos bastidores de algumas modalidades esportivas, a maior parte dos enquadramentos fotográficos é realizada em close ou com lentes macro. Ambos proporcionam proximidade com o objeto fotografado, revelando os detalhes.

Figura 1: Fita usada na ginástica rítmica

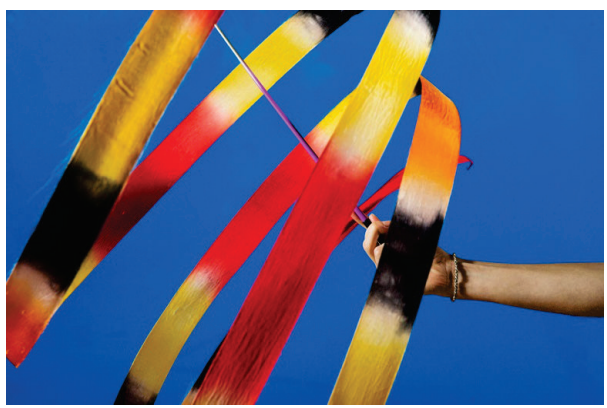

Fonte: Eduardo Knapp/Especial Microcosmo, Folha de S.Paulo, fev. 2016.

Nessa primeira imagem, vê-se um dos instrumentos de atletas da ginástica rítmica, a fita. Embora o público esteja habituado a ver ginastas usando a fita, a matéria “Aparelhos da ginástica são medidos e pesados" revela aspectos desconhecidos de quem assiste às competições, como o rigoroso controle do comprimento da fita, medida e pesada antes de cada apresentação. Nas Olimpíadas, informa o texto, o tamanho padrão é de $6 \mathrm{~m}$.

Outra revelação apresentada pela série é sobre o uso de cola 
na bola pelos jogadores de handebol. Para demonstrar o quanto o uso do produto garante a aderência da bola à mão do jogador, a foto mostra a mão sobre a bola:

Figura 2: Bola de handebol fixa na mão dos jogadores graças ao uso da cola

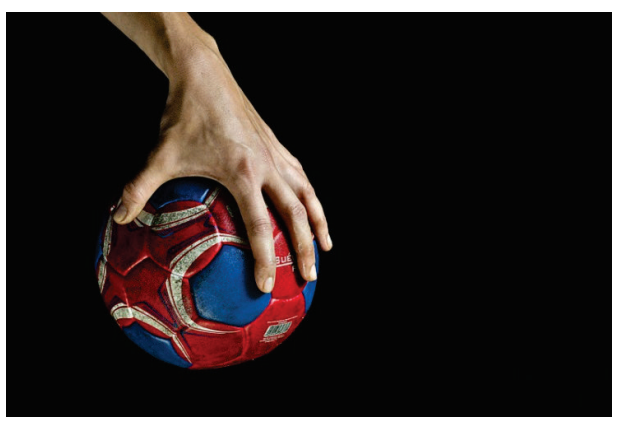

Fonte: Eduardo Knapp/Especial Microcosmo, Folha de S.Paulo, fev. 2016.

Já na matéria "Cola rápida ajuda bolinha a ser mais veloz e ganhar efeito", sobre o tênis de mesa, as fotografias mostram como funciona um procedimento quase completamente desconhecido por leigos: o uso da cola na raquete para garantir maior velocidade da bola em cada jogada.

Figura 3: Procedimento da aplicação de cola na raquete antes de cada partida

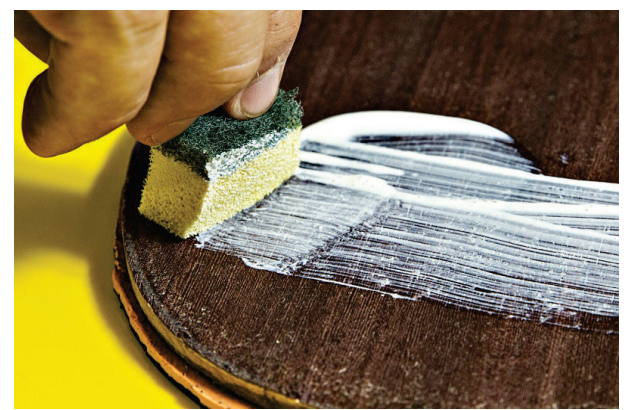


Fonte: Eduardo Knapp/Especial Microcosmo, Folha de S.Paulo, fev. 2016.

É evidente em todas as fotografias da série um cuidado especial com a qualidade de cada imagem, já que a revelação dos segredos de cada esporte ganharia maior credibilidade, sobretudo, a partir dessas imagens. Por isso, o repórter fotográfico responsável, Eduardo Knapp, que assina todas as fotografias, trabalhou também na pré-produção, utilizando técnicas frequentes na fotografia publicitária, com uso de contraste, figura e fundo, lentes macro e iluminação que permitissem a captação de detalhes.

Há também um padrão de cores usadas como fundo: amarelo, azul, preto, verde e vermelho - embora haja repetições de cores, as fotos de uma determinada modalidade são todas produzidas utilizando-se de uma mesma cor, evitando-se assim uma confusão na assimilação dos conteúdos. "A ideia dos fundos coloridos partiu do fotógrafo Eduardo Knapp, para criar uma unidade entre as fotos. Elas não são aleatórias. Usamos as cores dos aros olímpicos", explica a editora, Mariana Lajolo (2016).

Para garantir que os leitores compreendam os procedimentos mostrados, além da imagem principal que abre cada modalidade, do texto, do vídeo com atletas sendo entrevistados e de infográficos, há ainda uma pequena galeria de imagens sequenciadas, com botão de avançar e voltar, num procedimento didático nem sempre visto nos conteúdos produzidos pela mídia.

Figura 4: Sequência de imagens que mostra aplicação de cola na raquete

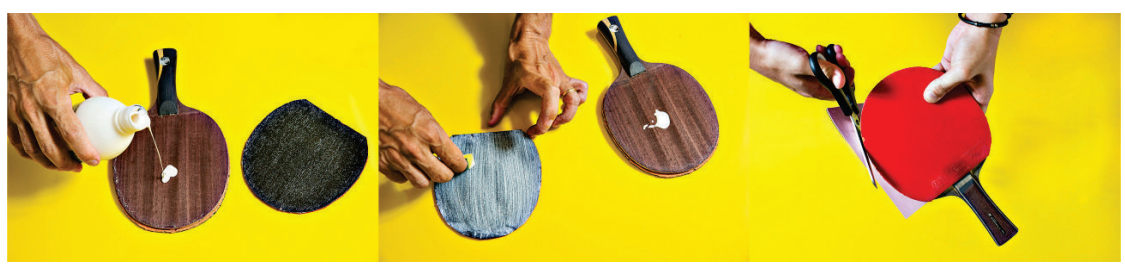


Fonte: Eduardo Knapp/Especial Microcosmo, Folha de S.Paulo, fev. 2016.

Como evidencia a imagem, apenas o objeto assunto do texto (no caso, a raquete de tênis de mesa, a cola, a esponja e a tesoura) e mãos que atuam na execução do procedimento aparecem nas imagens. A partir de uma construção estética minimalista, é possível tornar a informação mais evidente e, portanto, mais didática.

O texto sobre o tênis de mesa traz mais que os bastidores da modalidade esportiva. Revela também um truque irregular: o uso da cola rápida à base de solvente que dá vantagem extra aos atletas. O texto informa que, investigado numa espécie de "teste antidoping da raquete", o procedimento altera a tensão das fibras da borracha que reveste o equipamento. Um infográfico (Figura 5) é usado para ampliar a exemplificação da vantagem ilegal. Além dele, somente em outras duas modalidades esportivas são usados infográficos: o judô e o tiro olímpico. Nas três, observa-se a necessidade de reforçar a demonstração por meio de uma ilustração, já que a fotografia não dá conta de esquematizar a informação de forma elucidativa, como o faz a infografia e, mais ainda, o vídeo.

Para todas as modalidades esportivas foram produzidos vídeos que mostram, com detalhes, os segredos de cada esporte, garantindo espaço aos atletas que também colaboraram com a série nas entrevistas e posando para as fotografias que compõem o especial. Cada vídeo tem, em média, 1 minuto de duração, e foi produzido nos locais de treinos. A ideia foi colocar os atletas em ação, evidenciando o quanto os segredos revelados fazem parte de suas rotinas. 
92 Fotografia, didatismo e polissemia na série esportiva Microcosmo, do jornal Folha de S.Paulo

Figura 5: Infográfico sobre uso de cola na raquete do tênis de mesa e a vantagem irregular da cola rápida

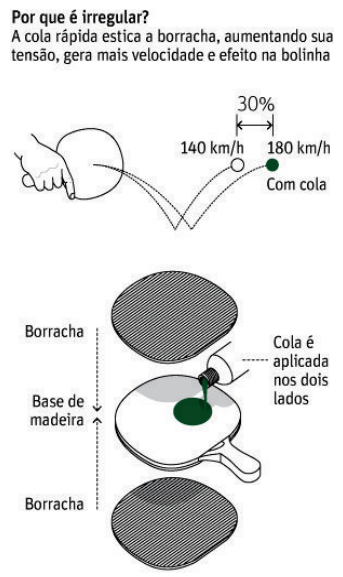

Fonte: Eduardo Knapp/Especial Microcosmo, Folha de S.Paulo, fev. 2016.

Em outra modalidade da série Microcosmo, sob o título "Nariz totalmente fechado é essencial dentro da água", é explicado o funcionamento de algo que faz parte das apresentações aquáticas: o uso de um pequeno clipe.

Figura 6 - Sequência de imagens que mostra o clipe de nariz em três situações diferentes

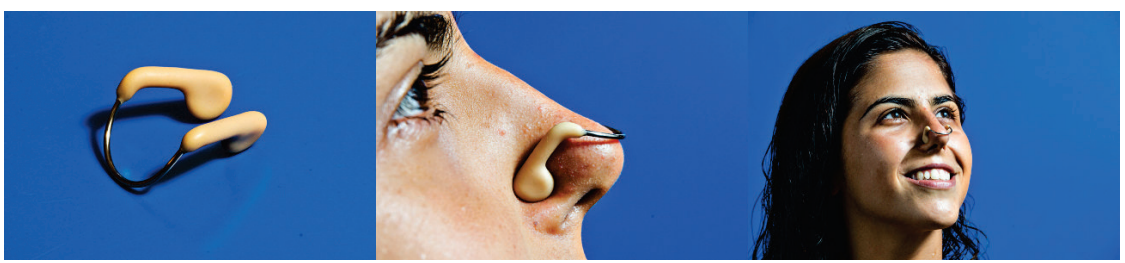

Fonte: Eduardo Knapp/Especial Microcosmo, Folha de S.Paulo, fev. 2016. 
Nesta galeria formada por três imagens, as fotos seguiram uma sequência que partiu da foto do objeto (o clipe), seguiu com a foto em superclose do clipe no nariz e outra, em ângulo um pouco mais aberto, do rosto da atleta usando o clipe e sorrindo.

$\mathrm{O}$ viés didático na produção e edição das imagens é evidente e busca, por meio da ideia da aderência do referente na fotografia, fundamentar e oferecer comprovação ao discurso textual ali presente.

O didatismo era importante nesse caso porque são detalhes que talvez a maioria dos leitores não conheça. Tínhamos de tentar mostrar de perto, nos ângulos que transmitissem mais informação e fossem fáceis de entender. Nas galerias do especial on-line, procurei mesclar fotos dos detalhes com as de atletas em ação, para que o leitor entenda como aquele equipamento é usado na prática (LAJOLO, 2016).

Desmistificando a "aura divina" dos atletas e revelando os bastidores do esporte para o público, a série atende ao ávido consumo dos leitores por imagens e, mais ainda, por informações as mais claras e didáticas possíveis. Entretanto, salienta-se também o fato de as imagens serem pré-produzidas (evidentemente não estamos falando de instantâneos fotográficos) e passarem por cuidadosa edição/manipulação, o que acentua fortemente seu caráter de representação:

A maioria das expressões contemporâneas de preocupação quanto à possibilidade de um mundoimagem estar tomando o lugar do mundo real continua a fazer eco, como no caso de Feuerbach, ao menosprezo platônico da imagem: verdadeira na medida em que se assemelha a algo real, falsa porque não passa de uma semelhança (SONTAG, 2004). 
Se, como afirma Sontag (2004, p.173), "quando algo é fotografado, torna-se parte de um sistema de informação", no caso do uso da fotografia na série Microcosmo a imagem fragmenta as continuidades do mundo e, conforme a autora, possibilita modos de controle inalcançáveis para o texto.

A exemplo do que defende Rouillé (2009, p.18), mesmo a fotografia de caráter documental não representa o real e atua na "fabricação" dos mundos:

Como o discurso e as outras imagens, o dogma de "ser rastro" mascara o que a fotografia, com seus próprios meios, faz ser: construída do início ao fim, ela fabrica e produz os mundos. Enquanto o rastro vai da coisa (preexistente) à imagem, o importante é explorar como a imagem produz o real. O que equivale a defender a relativa autonomia das imagens e de suas formas perante os referentes, ereavaliar o papel da escrita em face do registro.

Ao mesmo tempo, a relação entre esporte e estética é algo indissociável e contribui para a compreensão mais aprofundada do fenômeno esportivo, conforme Porpino (2003, p.148), de que "a visão do esporte como espetáculo também reflete significativamente essa presença dos elementos estéticos atrelados à prática esportiva $\mathrm{e}$ aponta para a questão da apreciação do esporte como possibilidade de vivência estética". Ao evidenciar o caráter imagético do esporte, através, sobretudo, da fotografia, a série amplia e fortalece essa relação.

\section{Jornalismo digital e polissemia}

É preciso compreender que o jornalismo digital e sua dinamicidade pressupõem a produção de conteúdos que nascem (e devem nascer) dentro da proposta de convergência midiática que é própria do meio: 
Os elementos que compõem o conteúdo on-line vão muito além dos tradicionalmente utilizados na cobertura impressa - textos, fotos e gráficos. Pode-se adicionar sequências de vídeo, áudio e ilustrações animadas. Até mesmo o texto deixou de ser definitivo - um e-mail com comentários sobre determinada matéria pode trazer novas informações ou um novo ponto de vista, tornandose, assim, parte da cobertura jornalística. E acessar um conteúdo não é necessariamente a leitura de uma notícia, já que engloba textos que trafegam pelas comunidades no Facebook, mensagens enviadas nos fóruns, resenhas de livros e discos e colunas (FERRARI, 2010, p. 39).

Ainda segundo Ferrari, a hipermídia, que permite ao leitor acessar a informação a partir de links, nasce a partir da influência das ciências cognitivas e da multimídia, tornando realidade o conceito de "texto elástico" (stretch text) ${ }^{2}$, no qual o mesmo, de acordo com as demandas do leitor, pode se expandir e contrair.

Se, como afirma George Landow (apud LEÃO, 1999, p. 42), vive-se a reconfiguração do autor, "que agora sofre uma erosão do self com a transferência do poder autoral para o leitor, que tem à sua disposição uma série de opções de escolha em seu percurso", essas possibilidades se ampliam e se reconfiguram a partir do fenômeno da convergência midiática, com galerias de imagens e vídeos curtos, próprios para aquele meio, como se observa na série Microcosmo.

Cabe ressaltar ainda o caráter polissêmico que um material produzido para a web possui, cruzando-se e entrecruzando-se com outros tantos significados e produzindo novas subjetividades, não observadas na leitura da versão impressa de um jornal, por exemplo:

as diferenças saltam aos olhos literalmente: a

2 Termo criado pelo filósofo e sociólogo norte-americano Ted Nelson, em 1963, hoje considerado o "pai do hipertexto". 
quantidade e qualidade de imagens, vídeos, fotos, músicas, conexões a crescentes links paralelos do mesmo grupo editorial etc transformam a experiência tranquila e privada da leitura em uma conexão contínua transitiva entre focos curtos e densos do ponto de vista da experiência visual e, de qualquer modo, sempre multirreceptivos (CANEVACCI, 2009, p. 229).

No caso do esporte, a partir do qual se constroem identidades, essa polissemia é ainda mais expressiva, especialmente se tomarmos a prática esportiva como "estratégia social", a exemplo do que Gumbrecht (2015, p.15-16) defendeu, e segundo o qual tanto a presença quanto a importância do esporte, cada vez mais em expansão no mundo contemporâneo, deve, sim, ocupar o lugar de algo que, em algum momento da história, a humanidade perdeu.

\section{Referências}

CANEVACCI, Massimo. Comunicação visual. São Paulo: Brasiliense, 2009.

FERRARI, Pollyana. Jornalismo digital. São Paulo: Contexto, 2010.

GUMBRECHT, Hans Ulrich. Perdido numa intensidade focada: esportes e estratégias de reencantamento. In: HELAL, Ronaldo; AMARO, Fausto (Orgs.). Esporte e mídia: novas perspectivas, a influência da obra de Hans Ulrich Gumbrecht. Rio de Janeiro: EdUERJ, 2015. p. 13-27.

LAJOLO, Mariana. Entrevista sobre a série Microcosmo, concedida por e-mail. Entrevistador: Janayna Ávila. 25 de maio, 2016. 
LEÃO, Lúcia. O labirinto da hipermídia. São Paulo: Iluminuras, 1999.

MICROCOSMO. Folha de S. Paulo. Disponível em: < http://arte.folha.uol.com.br/esporte/2016/microcosmo>. Acesso em: 10 maio 2016.

OWEN, Gibson. Tokyo Olympics: $€ 1,3 \mathrm{~m}$ payment to secret account raises questions over 2020 Games. The Guardian, Londres, 11 maio 2016. Disponível em <https://www.theguardian.com/ sport/2016/may/11/tokyo-olympics-payment-diack-2020-games $>$. Acesso em: 20 maio 2016.

PORPINO, Karenine de Oliveira. Interfaces entre corpo e estética: (re)desenhando paisagens epistemológicas e pedagógicas na educação física. In: LUCENA, Ricardo de Figueiredo; SOUZA, Edilson Fernandes (Orgs.). Educação física, esporte e sociedade. João Pessoa: Editora Universitária/UFPB, 2003.

QUADROS, Itanel. Uma introdução ao jornalismo visual ou à tessitura gráfica da notícia. Disponível em: <reposcom.portcom. intercom.org.br/bitstream/1904/17050/1/R0508-1.pdf>. Acesso em: 5 maio 2016.

ROUILLÉ, André. A fotografia: entre documento e arte contemporânea. São Paulo: Editora Senac São Paulo, 2009.

SONTAG, Susan. Sobre fotografia. São Paulo: Companhia das Letras, 2004. 